\title{
Perfil clínico y bacteriológico en pacientes con artroplastía tumoral de rodilla e infección periprotésica temprana
}

\author{
Clinical and bacteriological profile in patients with knee tumor \\ arthroplasty and early periprosthetic infection
}

\author{
Alcántara-Corona A, * Cario-Méndez G, ${ }^{\ddagger}$ Amaya-Zepeda RA, ${ }^{\S}$ Álvarez-Jiménez AV \\ Unidad Médica de Alta Especialidad Hospital de Ortopedia «Dr. Victorio de la Fuente Narváez», IMSS, Ciudad de México.
}

RESUMEN. Introducción: A nivel nacional e internacional son pocos los estudios sobre infección periprotésica tumoral temprana en rodilla. Presentamos una revisión de pacientes operados por artroplastía tumoral de rodilla, obteniendo información sobre el perfil clínico y bacteriológico de las infecciones periprotésicas tumorales tempranas. Material y métodos: Estudio observacional, retrospectivo y descriptivo. Revisión de expedientes de pacientes operados con artroplastía tumoral de rodilla del 01 de Enero de 2013 al 31 de Diciembre de 2017 y seguimiento mínimo de dos años. Resultados: 35 pacientes con edad promedio de 32 años, rodilla izquierda 71.4\%, 77.1\% afección en fémur distal, 54.2\% reportado osteosarcoma. Complicaciones en $82.8 \%$ de pacientes, retención protésica $62.8 \%$; la infección periprotésica representa $34.2 \%$ de las complicaciones de forma temprana en $90 \%$ de casos. Osteosarcomas y TCG presentaron infección temprana en igual proporción (44\%). La comorbilidad más común fue sobrepeso/obesidad en $66 \%$, tabaquismo en 55\%; $55 \%$ de pacientes infectados re-
ABSTRACT. Introduction: At the national and international levels, there are few studies on early knee tumor periprosthetic infection. We present a review of patients operated by knee tumor arthroplasty, obtaining information on the clinical and bacteriological profile of early tumor periprosthetic infections. Material and methods: Observational, retrospective and descriptive study, review of patient records with knee tumor replacement, from 1 January 2013, to 31 December 2017 and minimum follow-up of 2 years. Results: 35 patients with average age 32 . Left knee $71.4 \%, 77.1 \%$ distal femur, $54.2 \%$ was osteosarcoma. Complications in $82.8 \%$ of patients, prosthetic retention $62.8 \%$; periprosthetic infection accounts for $34.2 \%$ of early complications in $90 \%$ of cases. Osteosarcomas and GCT had early infection in equal proportion (44\%). The most common comorbidity was overweight/obesity at $66 \%$, smoking by $55 \%$. 55\% of infected patients received chemotherapy. 58\% of the isolated bacteria were Staphylococcus sp. $83.3 \%$ of

\section{Nivel de evidencia: IV}

* Médico Especialista en Traumatología y Ortopedia, Alta Especialización en Patología Tumoral Musculoesquelética, adscrito al Servicio de Cirugía de Tumores Óseos, Hospital de Ortopedia.

‡ Médico Especialista en Traumatología y Ortopedia, Alta Especialización en Patología Tumoral Musculoesquelética, Jefa del Servicio de Cirugía de Tumores Óseos, Hospital de Ortopedia.

${ }^{\S}$ Especialista en Traumatología y Ortopedia, Alta Especialización en Patología Tumoral Musculoesquelética, adscrito al Servicio de Cirugía de Tumores Óseos, Hospital de Ortopedia

" Médico residente de cuarto año en la Especialidad de Traumatología y Ortopedia IMSS-UNAM, UMAE de Traumatología, Ortopedia y Rehabilitación «Dr. Victorio de la Fuente Narváez».

Correspondencia:

Dr. Armando Alcántara-Corona

Tel: 5747-3500, ext. 25410,

E-mail: draca5971@yahoo.com

Recibido: 10-10-2020. Aceptado: 21-02-2021. 
cibió quimioterapia (neoadyuvante o adyuvante), 58\% de las bacterias aisladas fueron Staphylococcus sp. 83.3\% de bacterias mostraba resistencia, $66 \%$ de pacientes infectados requirió manejo radical. Conclusiones: La infección periprotésica temprana representa una patología devastadora en nuestra institución. Se logra retención protésica en 66\%. En nuestra unidad el perfil bacteriológico es resistente.

Palabras clave: Tumor, musculoesquelético, infección, artroplastía, bacteriológico

\section{Introducción}

La artroplastía tumoral de rodilla es una cirugía de salvamento de la extremidad; ${ }^{1,2,3}$ las tumoraciones óseas son susceptibles de manejo multidisciplinario debido a que se presentan en edades productivas de los pacientes y las tasas de supervivencia han aumentado con las radioterapias y quimioterapias, logrando una adecuada calidad de vida, llegando a buenos resultados en $95 \%$ de forma inmediata y hasta $80 \%$ de sobrevida a cinco años en tumoraciones malignas $^{1}$ En fuentes internacionales se ha reportado que usando la cirugía de salvamento de la extremidad en operaciones que involucran la rodilla, se logra una tasa de sobrevida de $75.9 \%$ a cinco años y $66.2 \%$ a 10 años, siendo la artroplastía con megaprótesis una de las cirugías más utilizadas que han permitido disminuir la tasa de amputaciones presentadas. $4,5,6,7$

El primero en clasificar las complicaciones fue Wirganowicz en 2011 y se dividían en dos rubros: fallas mecánicas y no mecánicas. Debido a lo amplio de estas divisiones, la International Society of Limb Salvage (ISOLS) generó diversas categorías para lograr un mejor abordaje y análisis ${ }^{8}$ (Tabla 1).

La frecuencia de infecciones periprotésicas asociadas al reemplazo de rodilla primario se sitúa en 0.68 y $1.60 \% .{ }^{9}$ En el caso de pacientes con patología tumoral, la inflamación crónica que sufren puede tener un papel en la inmunosupresión y en respuestas adversas a la presencia de bacterias y procesos traumáticos. Las alteraciones en las cifras de leucocitos se han asociado a un deficiente factor pronóstico en la progresión del tumor así como un mal pronóstico general del paciente. Se debe considerar que algunos pacientes están en sesiones de quimioterapia, por lo que el estado general del sistema inmunológico, el estado nutricional y la capacidad de cicatrización del paciente estaban comprometidos. ${ }^{10,11}$

En la cirugía de salvamento en patología tumoral se tienen cifras diferentes que van desde rangos de 6 y 7\% hasta series con reportes de 22 y $28 \%$, con valores máximos de $32 \%$ en pacientes sometidos a quimioterapia y radioterapia. ${ }^{11,12,13,14}$ De igual forma la clasificación de temporalidad de infección periprotésica de acuerdo con Henderson se divide en infección temprana (dentro de los dos primeros bacteria showed antibiotic resistance. $66 \%$ of infected patients required radical management. Conclusions: Early periprosthetic infection represents a devastating pathology in our institution. Prosthetic retention is achieved at $66 \%$. In our unit the bacteriological profile is resistant.

Keywords: Tumor, musculoskeletal, infection, arthroplasty, bacteriological. años de la cirugía) y tardía (después de los dos años de la cirugía). ${ }^{8}$

Las prótesis primarias y tumorales se rigen actualmente en caso de infecciones periprotésicas por la Musculoskeletal Infection Society (MSIS), quienes en 2011 unificaron la definición y criterios de infección periprotésica, la última revisión fue en 2018. Estos criterios se dividen en mayores y menores, permitiendo un enlace clínico/ laboratorial para lograr diagnosticar al paciente mediante criterios mayores absolutos (un criterio para diagnóstico) o criterios menores, ya sean preoperatorios (mayor o igual a seis criterios hacen diagnóstico) o criterios intraoperatorios (mayor o igual a seis criterios hacen diagnóstico). La clasificación puede usarse tanto para prótesis primarias como tumorales y la actual modificación a los criterios para el diagnóstico de una infección periprotésica nos permite una mayor inclusión de pacientes y de métodos para realizar un abordaje diagnóstico terapéutico completo. ${ }^{15}$

La serie de Pala reporta un porcentaje de infección de 9\% en 247 pacientes. Para tener un antecedente de agentes etiológicos más comunes en infección periprotéscia se recurrió a un estudio por Stephen J, en la que se hace una revisión de infecciones periprotésicas y de agentes aislados en el biofilm o membranas encontrados en la prótesis, reportando que en orden de frecuencia los agentes aislados son: Staphylococcus coagulasa negativo (30-43\%), Staphylococcus aureus (12-23\%), Streptococcus (9-10\%), Enterococcus (3-7\%), Gram negativos (3-6\%) y anaerobios (2-4\%).

Los artículos revisados no refieren el lado operado y no especifican a fondo el perfil clínico y bacteriológico de las prótesis tumorales de rodilla.

\section{Material y métodos}

Estudio observacional, retrospectivo y descriptivo de fuentes secundarias, usando el expediente clínico físico y electrónico y el registro de laboratorio disponibles en nuestra unidad. La muestra será no probabilística, de casos consecutivos, con pacientes con una artroplastía tumoral de rodilla, del 01 de Enero de 2013 al 31 de Diciembre de 2017 con una revisión mínima de dos años para poder cumplir con el criterio de infección temprana de la clasificación de ISOLS. Para determinar el diagnóstico de infección peripro- 
Tabla 1: Clasificación de fallo en cirugía de rescate de extremidad después de cirugía reconstructiva en tumoraciones óseas.

Categoría general/ Modalidad

Mecánica

Tipo 1: falla de tejidos blandos. Los tejidos se encuentran disfuncionales o deficientes, comprometiendo la función de la extremidad

Tipo 2: aflojamiento aséptico. Evidencia clínica y radiográfica de aflojamiento aséptico periprotésico

Tipo 3: fallo estructural. Ruptura, fractura o desgaste resultando en una estructura de soporte insuficiente

No mecánica

Tipo 4: infección periimplante. Reconstrucción infectada, no es posible la retención

Tipo 5: progresión tumoral. Progresión o recurrencia tumoral con contaminación y compromiso de la prótesis

Tipo 6: fallos pediátricos

Subcategoría

Descripción

1 A: funcional

$1 \mathrm{~B}$ : cobertura

2 A: temprano

2 B: tardío

3 A: implante

3 B: hueso

4 A: temprana

4 B: tardía

5 A: tejidos blandos

5 B: hueso

6 A: arresto fisiario

6 B: displasia articular
Función limitada debido a inserciones músculo ligamentarias insuficientes

Dehiscencia aséptica de herida

Aflojamiento aséptico antes de los dos años postimplantación de la prótesis

Aflojamiento aséptico después de dos años postimplantación de la prótesis

Ruptura o desgaste del implante, en caso de prótesis expansibles cualquier fallo en el alargamiento

Fractura ósea periprotésica

Infección que se diagnostica en los primeros dos años postoperatorios

Infección que se diagnostica después de dos años de la cirugía

Progresión tumoral en tejidos blandos que compromete prótesis

Progresión tumoral en tejido óseo que compromete prótesis

Arresto fisiario que resulta en deformidad angular o longitudinal

Articulación displásica por uso de implante

Tomado de: Henderson ER, et al. ${ }^{8}$

tésica se usarán los criterios establecidos por J Parvisi en 2018 en The Journal of Arthroplasty.

Criterios de inclusión: con diagnóstico de patología tumoral en rodilla a quienes se les haya hecho artroplastía total de rodilla con prótesis tumoral en nuestra unidad; con expediente clínico disponible, ya sea en físico o en electrónico para realizar la revisión.

Criterios de no inclusión: pacientes que hayan perdido el seguimiento en la consulta externa, que hayan fallecido antes de determinar si existieron complicaciones como infección periprotésica; pacientes cuyos expedientes ya no estén en activo, se hayan depurado o que los registros de expedientes se hayan dañado o con expedientes incompletos $\mathrm{y}$ registro insuficiente.

Métodos estadísticos: las variables continuas con una distribución normal se expresaron en medias y desviaciones estándar, aquéllas con distribución asimétrica con mediana y rango intercuartilar. Las variables categóricas se expresaron con número de observaciones y porcentajes. Se utilizó programa Software Microsoft Excel para gráficos y análisis.

\section{Resultados}

Se operó un total de 59 pacientes con reemplazo articular. No se incluyeron 24 pacientes en total: cinco por expediente físico dañado o incompleto y 19 por reemplazo articular tumoral en otra región diferente a la rodilla. Se analizó un total de 35 pacientes operados de artroplastía tumoral de rodilla (Figura 1).
De los 35 pacientes operados, a la mayoría se les realizó artroplastía tumoral de rodilla y a $34.2 \%$ se les realizó artroplastía de revisión, de los cuales 51.4\% fueron mujeres, la edad promedio fue de $32.4 \pm 17.2$ años. De las tumoraciones, $71.4 \%$ fueron en rodilla izquierda, el hueso de la rodilla más afectado por la patología tumoral fue el fémur en $77 \%$. De los procedimientos, $62.8 \%$ fueron secundarios a tumoraciones malignas y $37.1 \%$ por tumoraciones benignas, según el reporte de patología se detectaron 19 sarcomas (54.2\%), dos por metástasis de primario conocido (5.7\%), 12 por tumor de células gigantes (TCG) (37.1\%) y uno por TCG maligno (2.8\%).

En 82.8\% ( $\mathrm{n}=29)$ hubo complicaciones, pero en $17.1 \%$ ( $\mathrm{n}=$ seis) éstas no se observaron. De los 29 pacientes con complicaciones asociadas, $55.1 \%(\mathrm{n}=16)$ retuvieron la prótesis y $44.82 \%(n=13)$ requirieron de manejo radical de la extremidad: amputación en $84.5 \%$ de los pacientes $(\mathrm{n}=$ 11) y desarticulación de la extremidad en $15.3 \%(\mathrm{n}=$ dos$)$. De las 11 amputaciones, $(\mathrm{n}=$ siete) se realizaron en pacientes que tenían prótesis tumoral primaria y $(\mathrm{n}=$ cuatro $)$ en pacientes que tenían prótesis tumoral de revisión; los dos pacientes a quienes se les realizó desarticulación, tenían prótesis tumoral primaria.

Se clasificó a los 29 pacientes con complicaciones según la propuesta de Henderson en la ISOLS, se reportaron con infección periprotésica 34.4\% $(n=10)$, de las cuales $n=$ nueve $(90 \%)$ tempranas y $\mathrm{n}=$ una $(10 \%)$ tardía, fallo estructural $n=$ ocho, de los cuales ocho (100\%) secundarios a fallo del implante, defectos asociados a tejidos blandos $n$ = seis, donde seis $(100 \%)$ fueron por defecto de cobertu- 
ra, aflojamiento aséptico $\mathrm{n}=$ cuatro, de los cuales $\mathrm{n}=\operatorname{dos}$ (50\%) fueron tempranos y $\mathrm{n}=$ dos $(50 \%)$ fueron tardíos, progresión tumoral $n=$ uno, donde $n=$ uno $(100 \%)$ fue secundario a progresión de la tumoración ósea; no se reportaron complicaciones de tipo pediátrico.

Según el estudio histopatológico de los pacientes operados por artroplastía tumoral de rodilla, $62.8 \%(\mathrm{n}=22)$ reportó una tumoración maligna y 37.1\% $(\mathrm{n}=13)$ tumoración benigna. Dentro de las tumoraciones malignas $45.7 \%$ ( $n=$ 16) correspondió a un osteosarcoma y $17.1 \%$ ( $\mathrm{n}=$ seis) secundario a otras tumoraciones malignas, de las tumoraciones benignas 100\% $(n=13)$ correspondió a tumor de células gigantes (Tabla 2).

De los 22 pacientes con reporte histopatológico de malignidad, a $81.8 \%(n=18)$ se les dio manejo con alguna forma de quimioterapia; $72 \%(\mathrm{n}=13)$ recibió quimioterapia neoadyuvante y adyuvante; $16.6 \%(\mathrm{n}=$ tres) recibió sólo quimioterapia adyuvante y $11.1 \%(\mathrm{n}=$ dos$)$ recibieron sólo quimioterapia adyuvante.

\section{Análisis de pacientes con infección periprotésica temprana}

De 35 pacientes en nuestro estudio, 28.5\% $(n=10)$ cursó con infecciones periprotésicas, de las cuales $90 \%(\mathrm{n}=$ nueve) se presentaron de forma temprana y $10 \%$ ( $n=$ una) de forma tardía.

De los nueve pacientes con complicación 4 A, 66.6\% fueron hombres $(\mathrm{n}=$ seis) y $33.3 \%$ mujeres $(\mathrm{n}=$ tres); la edad promedio de los pacientes fue $31 \pm 11$ años. Todas las complicaciones se presentaron en artroplastía tumoral de rodilla primaria; afección del fémur en ( $\mathrm{n}$ = cuatro); tibia
( $\mathrm{n}=$ cuatro) y ( $\mathrm{n}=$ una) con afección simultánea en fémur y patela. La rodilla más afectada fue la del lado izquierdo ( $\mathrm{n}=$ siete) y en rodilla derecha $(\mathrm{n}=$ dos). Las tumoraciones malignas en ( $\mathrm{n}=$ cinco), siendo $44.4 \%$ de los tumores secundarios a sarcomas (cuatro), 11.1\% tumor metastásico ( $\mathrm{n}=$ uno) por carcinoma renal de células claras. Los tumores fueron benignos ( $\mathrm{n}=$ cuatro), siendo todos los pacientes reportados con tumor de células gigantes.

De los nueve pacientes con complicación tipo 4 A de ISOLS, la comorbilidad más reportada fue sobrepeso en $66 \%$ de los pacientes ( $n=$ seis); en segundo lugar fue el tabaquismo en $55 \%$ de los pacientes ( $\mathrm{n}=$ cinco), tabaquismo negado en 33\% de los pacientes ( $\mathrm{n}=$ tres); después hipertensión arterial en $22 \%(\mathrm{n}=$ dos); cáncer renal en $11.1 \%(\mathrm{n}=$ uno) y caries en $11.1 \%(n=1)$. Debido a situaciones fuera del control del estudio se constató que $11 \%$ de pacientes (n $=$ uno) no se especificaba si existía o no tabaquismo y $33 \%$ de los pacientes $(\mathrm{n}=$ tres$)$ no tenían registrado el índice de masa corporal (IMC), el IMC se registra en consulta antes de realizar la artroplastía tumoral. De los nueve pacientes con infección periprotésica temprana, 33.3\% ( $\mathrm{n}$ = tres) mostraban más de una comorbilidad.

Para el diagnóstico de infección periprotésica se usaron como referencia los criterios propuestos por el Bone \& Joint Journal; $100 \%$ de los pacientes presentó un criterio mayor -fístula que comunica con la prótesis- con el cual se hizo el diagnóstico. Se completó el protocolo de los pacientes mediante la toma de cultivos para identificar el agente causal así como el reporte de histopatología, revisión de la evolución y desenlace de la prótesis (considerando retención o manejo radical de la extremidad) y se revisó si los pacientes recibieron manejo con quimioterapia adyuvante o neoadyu-

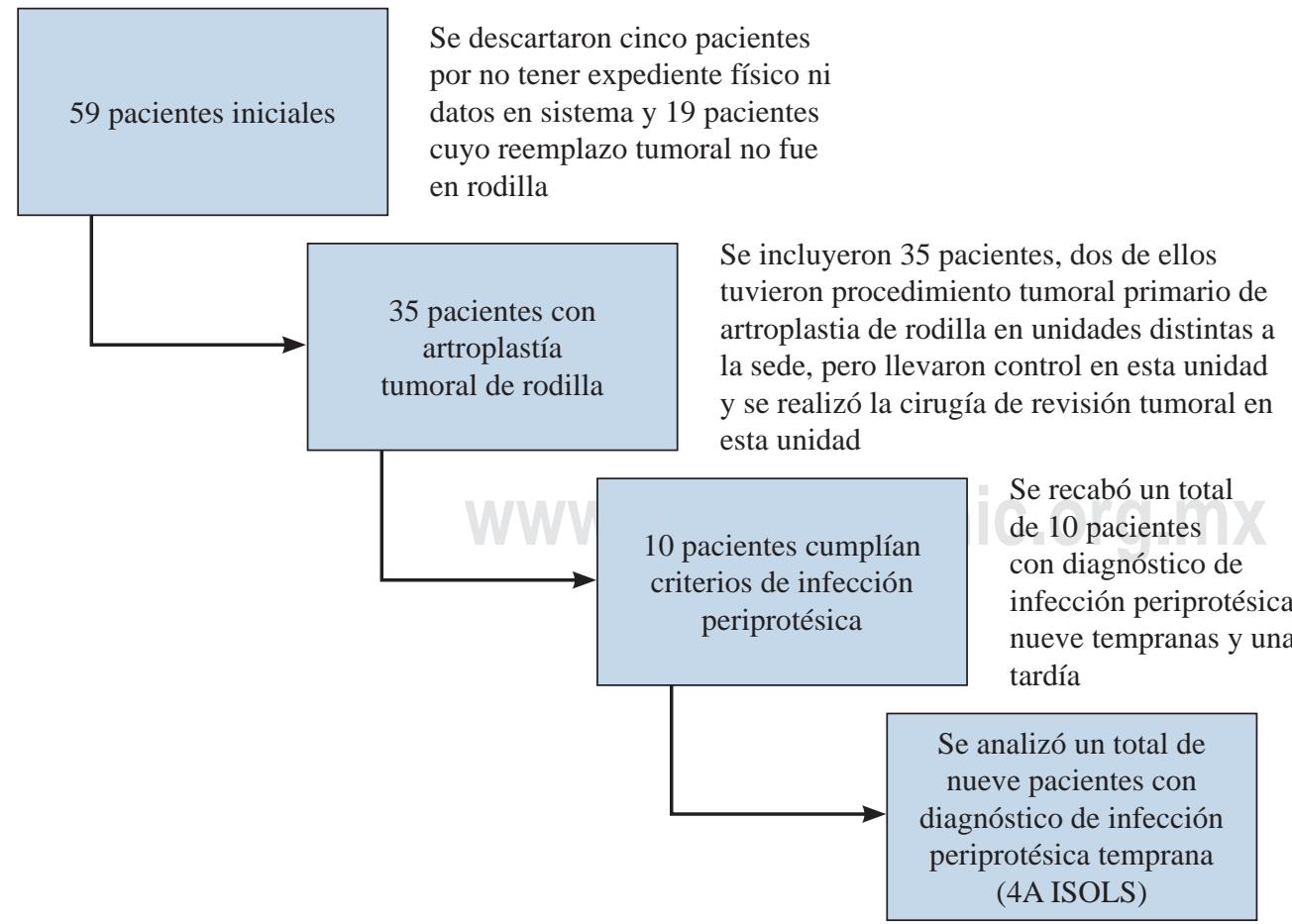

Figura 1:

Pacientes reclutados para reemplazo articular tumoral de rodilla en el estudio. 


\begin{tabular}{|c|c|}
\hline \multicolumn{2}{|c|}{$\begin{array}{l}\text { Tabla 2: Reporte histopatológico de pacientes con } \\
\text { artroplastía tumoral de rodilla. } \mathrm{N}=35 \text {. }\end{array}$} \\
\hline Reporte patología & n (\%) \\
\hline Tumor de células gigantes & $13(37.14)$ \\
\hline Osteosarcoma total & $16(45.70)$ \\
\hline Otros & $6(17.1)$ \\
\hline \multicolumn{2}{|l|}{ Desglose reportes patología maligna } \\
\hline \multicolumn{2}{|l|}{ Osteosarcomas } \\
\hline Osteoblástico & $7(30)$ \\
\hline Condroblástico & $3(8.5)$ \\
\hline Parostal & $2(5.7)$ \\
\hline Fibroblástico & $2(5.7)$ \\
\hline Pleomófico & $2(5.7)$ \\
\hline \multicolumn{2}{|l|}{ Otros } \\
\hline Condrosarcoma & $2(5.7)$ \\
\hline Metástasis* & $2(5.7)$ \\
\hline Tumor de células gigantes maligno & $1(2.8)$ \\
\hline Histiocitoma fibroso maligno & $1(2.8)$ \\
\hline
\end{tabular}

vante, ambas formas de quimioterapia o ninguna forma de quimioterapia.

Los pacientes con complicación 4 A de ISOLS presentaron la infección periprotésica en promedio durante los primeros 4.2 meses del postquirúrgico (4.2 \pm 5.7 ); se les realizó en promedio $3 \pm 1.9$ procedimientos quirúrgicos en su protocolo para control de la infección, estos procedimientos eran aseos con desbridamiento quirúrgico, tomas de cultivo, uso de sistemas de presión negativa, manejo conjunto con cirugía plástica y reconstructiva para rotación de colgajo.

De los nueve pacientes, $66.6 \%(\mathrm{n}=$ seis) requirieron manejo radical y éstos conservaron la prótesis durante un promedio de $16.6 \pm 8.4$ meses antes de realizarse amputación 83.3\% ( $\mathrm{n}=$ cinco) o desarticulación de la extremidad 16.6\% $(\mathrm{n}=\mathrm{uno})$. De las cinco amputaciones efectuadas, $80 \%(\mathrm{n}=$ cuatro) se realizaron a nivel supracondíleo y $20 \%$ ( $\mathrm{n}=$ una) se hizo a nivel subtrocantérico. Entre las complicaciones asociadas al manejo radical se reportó el síndrome de miembro fantasma y en el paciente que requirió desarticulación, se presentó infección persistente en sitio de desarticulación.

De estos pacientes, $55.5 \%(\mathrm{n}=$ cinco) recibieron quimioterapia, de éstos, $60 \%(\mathrm{n}=$ tres) recibieron quimioterapia neoadyuvante y adyuvante y $40 \%(\mathrm{n}=$ dos$)$ recibieron sólo quimioterapia adyuvante, a ningún paciente se le realizó manejo con quimioterapia neoadyuvante como único esquema y $44.4 \%$ (n = cuatro) no recibieron ninguna forma de quimioterapia.

Agentes aislados: se tienen considerados 14 agentes. Con confirmación por cultivo $85 \%(\mathrm{n}=12)$, en $7.14 \%(\mathrm{n}$ = uno) no se logró cultivar al agente etiológico y en 7.14\% $(\mathrm{n}=$ uno) no se encontró registro del cultivo en expediente.

De los 12 agentes etiológicos identificados, $83.3 \%(\mathrm{n}=$ 10) corresponde a bacterias Gram positivas y $16.6 \%$ ( $n=$ dos) corresponde a bacterias Gram negativas. En estas bacterias $66.6 \%(\mathrm{n}=$ ocho) presentaban metabolismo aerobio $\mathrm{y}$ $33.3 \%$ ( $=$ cuatro) de las bacterias cultivadas eran de me- tabolismo anaerobio. De las bacterias, 50\% (n = seis) mostraban resistencia simultánea a la penicilina y a la vancomicina, $41.6 \%(\mathrm{n}=$ cinco) mostraban sensibilidad intermedia a ambos antibióticos y 8.3\% ( $\mathrm{n}=$ una) no tenía reporte de sensibilidad en el sistema de laboratorio.

De los nueve pacientes con infección periprotésica temprana, 55.5\% $(\mathrm{n}=5)$ evidenciaban dos agentes etiológicos de forma simultánea en el cultivo, 22.2\% ( $\mathrm{n}=$ dos) presentaban un solo agente etiológico, $11.1 \%(\mathrm{n}=$ uno) mostraba cultivos sin crecimiento bacteriano (pese a cuadro clínico franco) y $11.1 \%$ ( $n=$ uno) no tenía reportado ningún cultivo en el sistema. De los 12 agentes aislados $66.6 \%(\mathrm{n}=$ ocho) corresponden a flora residente de la piel y $33.3 \%(\mathrm{n}=$ cuatro) corresponden a flora considerada nosocomial; $58.3 \%$ (n = siete) de las bacterias son Staphylococcus, 16\% (n = dos) corresponde a Enterococcus, $8.3 \%(\mathrm{n}=\mathrm{una})$ a Kokuria, $8.3 \%$ ( $=$ una) a Enterobacter y $8.3 \%(\mathrm{n}=$ una) a Escherichia. De las bacterias, $83.3 \%(\mathrm{n}=10)$ mostraba alguna forma de resistencia o sensibilidad indeterminada a penicilina y vancomicina, $8.3 \%$ presentaba sensibilidad indeterminada a vancomicina y sensibilidad a oxacilina y $8.3 \%(n=u n a)$ no tenía reporte de antibiograma.

La sensibilidad global descrita de los agentes bacterianos fue a clindamicina, meropenem, quinutripsina, moxifloxacino, eritromicina, tigeciclina, levofloxacino y oxacilina (sólo $S$. lentus). De estos nueve pacientes, $33.3 \%(\mathrm{n}=$ tres) contaban con reporte de histopatología después del retiro de prótesis que confirmaba el diagnóstico, 33.3\% ( $\mathrm{n}=$ uno) especificaba infiltrado celular compatible con infección, 33.3\% (n = uno) reportaba osteomielitis y 33.3\% ( $\mathrm{n}=$ uno) describía el hallazgo de membranas periprotésicas, en el reporte de membranas de este paciente se asentaba que en ninguno de sus cultivos había crecimiento bacteriano (Tabla 3).

\section{Discusión}

En nuestro estudio la proporción de pacientes con artroplastía tumoral de rodilla en hombres y mujeres (48 y 51\%, respectivamente) se mantuvo congruente con la literatura internacional, aunque con ligeras variaciones donde se invierten los porcentajes (Smolle y Medellin). De las patologías tumorales, $70 \%$ se presentaron en rodilla izquierda y $77 \%$ de las infecciones fueron en lado izquierdo, durante el análisis de datos se observó este hallazgo y si bien no está descrito en otros artículos, el predominio en nuestra unidad es importante, por lo que se incluyó en el análisis.

En el caso de infección periprotésica nuestro estudio arrojó un predominio de 66.6\%, en los artículos de la literatura internacional por lo general no se menciona la proporción. Se evidencia en los estudios internacionales y en el nuestro que la mayor proporción de patologías corresponde a las tumoraciones malignas en 62\%; siendo el primer lugar los osteosarcomas que comprenden $72 \%$ de las tumoraciones malignas reportadas. En series internacionales las proporciones de tumoraciones malignas son variables, ya que algunos estudios reportan hasta $83 \%$ de tumoraciones ma- 
lignas tipo sarcoma (Pala), la edad de igual forma se mantiene en un promedio de 33 años en nuestro estudio y 32 años en series internacionales (Pala), con una variación de edades promedio, siendo 18 el promedio en los artículos con pacientes más jóvenes o de 25 años (Smolle).

La importancia de las artroplastías tumorales radica también en la sobrevida que tienen, siendo que los pacientes oncológicos con patología por sarcomas presentan una supervivencia de cinco a 10 años (GPC) y la prótesis tiene un promedio de vida similar; es importante considerar la cirugía de salvamento como una opción terapéutica para estos pacientes. Se reporta sobrevida de prótesis a cinco años de $71 \%$ y a 10 años de 63\% (Medellin), sobrevida de 95 y 74\% a los cinco y 10 años (Smolle) en pacientes con edad promedio de 18 años hasta series donde la retención del implante fue de $43 \%$ (Smolle). En nuestro estudio la retención de la prótesis de forma global fue de $62 \%$, pese a que se presentaron complicaciones en $82 \%$ de los pacientes. La literatura internacional describe 41 y 57\% complicaciones en la serie de pacientes estudiados (Smolle). Sobre la infección peripro-

\begin{tabular}{|c|c|}
\hline \multicolumn{2}{|c|}{$\begin{array}{l}\text { Tabla 3: Reporte y perfil bacteriológico en } \\
\text { pacientes con infección periprotésica temprana } \\
\text { tumoral de rodilla (4A de ISOLS). }\end{array}$} \\
\hline Pacientes $4 \mathrm{~A}, \mathrm{~N}=9$ & n (\%) \\
\hline Agente único & $2(22.2)$ \\
\hline Dos agentes & $5(55.5)$ \\
\hline Sin reporte* & $1(11.1)$ \\
\hline Sin crecimiento ${ }^{\ddagger}$ & $1(11.1)$ \\
\hline \multicolumn{2}{|l|}{ Características agentes aislados, $\mathrm{N}=12$} \\
\hline Gram positivo & $10(83.3)$ \\
\hline Gram negativo & $2(16.6)$ \\
\hline Aerobio & $8(66.6)$ \\
\hline Anaerobio & $4(33.3)$ \\
\hline \multicolumn{2}{|l|}{ Agentes etiológicos aislados. $\mathrm{N}=12$} \\
\hline Staphylococcus & $7(58.3)$ \\
\hline Staphylococcus epidermidis (RV) (RP) & $2(28.5)$ \\
\hline Staphylococcus productor de betalactamasa (I) & $1(14.2)$ \\
\hline Staphylococcus klossi (I) & $1(14.2)$ \\
\hline Staphylococcus aureus (SRS) & $1(14.2)$ \\
\hline Staphylococcus haemolitycus (I) & $1(14.2)$ \\
\hline Staphylococcus lentus (I) (sensible oxacilina) & $1(14.2)$ \\
\hline Otros & $5(41.6)$ \\
\hline Enterococcus faecalis (RV) (RP) & $2(40.0)$ \\
\hline Kokuria kristinae (RV) (RP) & $1(20.0)$ \\
\hline Enterobacter cloacae (RV) (RP) & $1(20.0)$ \\
\hline Escherichia coli (I) & $1(20.0)$ \\
\hline \multicolumn{2}{|l|}{ Sensibilidad y resistencia. $N=12$} \\
\hline Resistencia a penicilina (RP) & $6(50.0)$ \\
\hline Resistencia a vancomicina (RV) & $6(50.0)$ \\
\hline Indeterminado (I) & $5(41.6)$ \\
\hline Sin reporte de sensibilidad (SRS) & $1(8.3)$ \\
\hline \multicolumn{2}{|l|}{ Confirmación histopatología. $\mathrm{N}=3$} \\
\hline Infiltrado compatible con infección & $1(33.3)$ \\
\hline Osteomielitis & $1(33.3)$ \\
\hline Membrana periprotésica $^{\ddagger}$ & $1(33.3)$ \\
\hline \multicolumn{2}{|c|}{$\begin{array}{l}\text { * Paciente con diagnóstico clínico de infección periprotésica, fístula de alto } \\
\text { gasto con exudado purulento. Captado en seguimiento por UMAE, Veracruz. } \\
\text { ₹ Paciente que reportaba cultivos sin crecimiento pese a hallazgos clínicos } \\
\text { francos de infección; en reporte por histopatología en retiro de prótesis y } \\
\text { amputación se reporta presencia de membranas periprotésicas. }\end{array}$} \\
\hline
\end{tabular}

tésica existen reportes variados, ya que comparan diferentes procedimientos de salvamento (resurface y artroplastías unicompartimentales con megaprótesis) y no se hace diferencia entre la presentación de infección periprotésica temprana del tipo 4 A o del tardío del tipo 4 B. En nuestro estudio se reportaron complicaciones $4 \mathrm{~A}$ en nueve de 35 pacientes (25\%) que corresponde a $90 \%$ de la presentación de infecciones en el estudio (un paciente fue clasificado como complicación 4 B que corresponde a 10\%). Las infecciones periprotésicas pueden presentarse de 9, 16 y 57\% (Smolle), 18\% (Medellin), 9\% (Pala) y $8 \%$ (Capanna).

La infección en reemplazo articular tumoral de rodilla se manifiesta en un porcentaje mucho mayor en comparación con una prótesis primaria de rodilla, reportándose porcentajes de 1\% (GPC) y 1.25\% (Haddad). El manejo clínico y quirúrgico de una infección periprotésica puede ascender los costos de una prótesis primaria hasta 2.8 veces sobre el costo de una revisión por aflojamiento y de forma global un manejo clínico quirúrgico con cirugía de artroplastía de revisión por infección eleva el costo del procedimiento hasta 4.8 veces (Haddad). Considerando que una prótesis tumoral es más costosa, sólo se realiza en un centro de tercer nivel y requiere mayor seguimiento por la patología base asociada; las infecciones y manejo subsecuente implican un costo muy elevado para un sistema de salud pública. En nuestro estudio $66.6 \%$ de los pacientes con infección periprotésica requirieron de manejo radical mediante amputación o desarticulación; en series internacionales se maneja un porcentaje de manejo radial de 14 a 37\% según el tipo de prótesis utilizada para la revisión, en el estudio revisado usan una de tipo silver coating, (Smolle), en nuestra unidad no se cuenta con prótesis con recubrimiento de plata, la cual se reporta, mejora el pronóstico en caso de infecciones periprotésicas tumorales. La infección se presentó en los primeros cuatro meses postquirúrgicos, este dato no es evaluado en la literatura internacional consultada, sólo se menciona la sobrevida global y en algunos casos si la clasificación fue temprana antes de los dos años o tardía después de los dos años. Se realizaron en promedio tres cirugías de desbridamiento e intento de salvamento antes del manejo radical, en nuestra institución no se tiene el acceso completo a prótesis con recubrimiento de plata y en ningún paciente se realizó prótesis de revisión en casos de infección, por lo que no se puede comparar con el manejo DAIR en dos etapas descrito en otros artículos. El tiempo promedio de retención en meses de los pacientes fue de 16 , dato que no se especifica en otras series, sólo engloban sobrevida a dos, cinco y 10 años, pero no se especifica el tiempo en meses. Se considera que esto es importante, ya que por las características de nuestra población, que en su mayoría son trabajadores asegurados (de 23 de 35 pacientes -65.71\%-), esos meses permiten una reincorporación a las actividades de la vida diaria y mejoran la situación global del paciente antes de someterse a un manejo radical. La quimioterapia se ha considerado un factor de riesgo ante el desarrollo de infecciones aunado a la inmunosupresión presente en pacientes con patología oncológica 
(Gonzalez), en particular cuando se hace manejo adyuvante. De los nueve pacientes que mostraron infección periprotésica temprana, 55\% tuvo alguna forma de quimioterapia. De 35 pacientes estudiados, a 18 se les realizó alguna forma de quimioterapia y cinco de ellos presentaron infección periprotésica, representando 28\%. Estos datos no se encuentran en otros estudios, de la misma forma que el tabaquismo y sobrepeso u otras comorbilidades no se mencionan en los artículos revisados, éstos son factores que en prótesis primarias sí han demostrado tener influencia en el pronóstico (GPC).

Sobre los reportes de los cultivos, pese a que la literatura nacional e internacional menciona que los organismos aislados con mayor frecuencia corresponden a la flora normal de la piel, estos hallazgos no se describen en los artículos revisados al igual que la sensibilidad de las bacterias aisladas. Capanna recomienda el uso de profilaxis antibiótica con vancomicina, pero esto es debatible, ya que los agentes aislados en nuestra unidad han reportado resistencia no sólo a penicilinas, sino a vancomicina, mostrando sensibilidad a antibióticos de segunda y tercera línea para manejo de infecciones periprotésicas, por lo cual se cree que es importante tomarlo en consideración para el protocolo de tratamiento y seguimiento de nuestros pacientes y en el manejo antibiótico que se otorga en los casos que se indica para uso en domicilio. El agente aislado más común fue Staphylococcus $58.3 \%$ (siete) y de éstos 28\% (dos) presentaron resistencia a penicilinas y vancomicina, 57\% (cuatro) con sensibilidad indeterminada, un paciente con sensibilidad no reportada, dejando un global de $80 \%$ de resistencia o sensibilidad indeterminada, lo cual refuerza la noción de que los esquemas antibióticos profilácticos en pacientes con patología tumoral deben ser diferentes al que se usa en prótesis primarias no tumorales.

\section{Perspectivas y limitantes del estudio}

Los pacientes operados en nuestra institución para artroplastía tumoral de rodilla reportan tumoraciones de $8 \mathrm{~cm}$ en promedio (registro de 28 de los 35 pacientes en el estudio), las tumoraciones a mayor tamaño requieren de márgenes de seguridad más amplios y disminuyen el stock óseo disponible para la cirugía, esto hace las cirugías aún más complejas en su planificación y técnica quirúrgica y de la misma forma, a mayor tamaño de la tumoración mayor el riesgo de complicaciones asociadas y un detrimento en el pronóstico del paciente.

Los expedientes a recabar fueron limitados debido a situaciones como el deterioro y eliminación de expedientes en físico del archivo clínico (expedientes con más de cinco años y expedientes dañados durante el sismo del 19 de Septiembre de 2017) así como la migración del expediente electrónico del IMSS a una plataforma nueva (pasando de SICEH a ECE).

La perspectiva del estudio es lograr recabar un perfil de los pacientes que tienen complicaciones y de forma con- creta los que presentan infección periprotésica temprana, debido a las complicaciones graves asociadas sobre la retención de la prótesis, la calidad de vida del paciente por la patología agregada y por la limitación que supone una amputación o desarticulación. Este perfil nos permitirá usar la información para modificar los protocolos de seguimiento a pacientes; en este momento se hace la primera cita a las tres semanas posteriores al egreso hospitalario con citas subsecuentes al mes, seis meses y al año. Según los resultados, se pueden valorar y modificar los esquemas antibióticos profilácticos y los de tratamiento en espera de cultivos, así como la implementación de medidas de vigilancia más frecuentes en caso de sospecha de infección periprotésica durante los primeros cuatro meses del postquirúrgico y abordar de forma temprana las comorbilidades de pacientes.

Queda claro que la literatura nacional e internacional es limitada debido a la naturaleza de la patología y al manejo de rescate de extremidades. Se considera relevante el hecho de que en diversos artículos no se hace énfasis en los agentes etiológicos aislados ni en su sensibilidad o resistencia. Este estudio pone de manifiesto que si bien las bacterias aisladas corresponden con las reportadas en infecciones de prótesis primarias y con algunos artículos revisados, no corresponden al manejo antibiótico profiláctico sugerido (vancomicina y penicilinas), ya que las bacterias demostraron resistencia a los esquemas usualmente recomendados en la literatura nacional e internacional; este estudio podría apoyar la recomendación del cambio en profilaxis antibiótica. El análisis de comorbilidades no se describe de forma enfática en otros artículos ni se destacan factores de riesgo en cuanto a comórbidos y quimioterapia, pero valdría la pena modificar el seguimiento a pacientes que presentan alteraciones en peso (sobrepeso y obesidad) y tabaquismo confirmado sin importar su intensidad.

\section{Conclusiones}

Este estudio nos demuestra complicaciones en $82 \%$ de los pacientes, 62\% logran la retención del implante y en el caso de infecciones periprotésicas, éstas se presentan en los primeros cuatro meses del seguimiento postquirúrgico del paciente. La retención promedio es de 16 meses antes del manejo radical, lo cual da un tiempo considerable de adaptación del paciente y de preparación para manejo radical. En el caso de infecciones periprotésicas el porcentaje de manejos radicales se mantiene similar al de la visión global de las complicaciones de las prótesis tumorales.

Consideraciones éticas: Este estudio se llevó a cabo siguiendo los acuerdos estipulados en la Ley General de Salud.

Es una investigación sin riesgo. Este trabajo se presentó ante el comité local de investigación para su evaluación y dictaminación, siguiendo los códigos internacionales: Declaración de Helsinki de la Asociación Médica Mundial, principios éticos para las investigaciones médicas en seres humanos. 
Referencias

1. Secretaría de Salud. Diagnóstico oportuno de osteosarcoma en niños y adolescentes en primer y segundo nivel de atención médica. Guía Práctica Clínica. 2013: 1-52.

2. Greenspan A, Jundt G, Remagen W. Differential diagnosis in orthopaedic oncology. $2^{\text {nd }}$, Philadelphia, Pa.: Lippincott Williams \& Wilkins 2007.

3. Secretaría de Salud. Tratamiento de los tumores benignos de tejidos blandos en adultos en el tercer nivel de atención. Guía Práctica Clínica. 2012: 43. Disponible en: www.cenetec.salud.gob.mx.

4. Capanna R, Scoccianti G, Frenos F, Vilardi A, Beltrami G, Campanacci DA. What Was the survival of megaprostheses in lower limb reconstructions after tumor resections? Clin Orthop Relat Res. 2015; 473(3): 820-30. doi: 10.1007/s11999-014-3736-1.

5. Smolle MA, Andreou D, Tunn PU, Leithner A. Advances in tumour endoprostheses: a systematic review. EFORT Open Rev. 2019; 4(7): 445-59. doi: 10.1302/2058-5241.4.180081.

6. Pala E, Trovarelli G, Calabro T, Angelini A, Abati CN, Ruggieri P. Survival of modern knee tumor megaprostheses: failures, functional results, and a comparative statistical analysis. Clin Orthop Relat Res. 2015; 473(3): 891-9. doi: 10.1007/s11999-014-3699-2.

7. Medellin MR, Fujiwara T, Clark R, Stevenson JD, Parry M, Jeys L. Mechanisms of failure and survival of total femoral endoprosthetic replacements. Bone Joint J. 2019; 101B(5): 522-8. doi: 10.1302/0301-620X.101B5.BJJ-2018-1106.R1.

8. Henderson ER, O’Connor MI, Ruggieri P, Windhager R, Funovics PT, Gibbons CL, et al. Classification of failure of limb salvage after reconstructive surgery for bone tumours: A modified system including biological and expandable reconstructions. Bone Joint J. 2014; 96B(11): 1436-40. doi:10.1302/0301-620X.96B11.34747.
9. Arano MM, Huerta GG, Tena SM, VRJ. Diagnóstico y tratamiento de las infecciones asociadas a dispositivos ortopédicos prótesis y/o material de osteosíntesis. Guía Práctica Clínica gpc. 2013, 1-66. www.cenetec.salud.gob.mx.

10. Gonzalez H, Hagerling C, Werb Z. Roles of the immune system in cancer: from tumor initiation to metastatic progression. Genes Dev. 2018; 32(19-20): 1267-84. doi: 10.1101/GAD.314617.118.

11. Zuidhof R-JWJ, Lowik CAM, Ploegmakers JJW, Dijkstra SPD, Wouthuyzen-Bakker M, Jutte PC. Periprosthetic joint infection in orthopaedic surgical oncology. Ann Joint. 2019; 4: 26-26. doi: 10.21037/aoj.2019.05.01.

12. Haddad FS, Ngu A, Negus JJ. Prosthetic joint infections and cost analysis? Adv Exp Med Biol. 2017; 971: 93-100. doi: 10.1007/5584_2016_155.

13. Janz V, Lochel J, Trampuz A, Schaser KD, Hofer A, Wassilew GI. Risk factors and management strategies for early and late infections following reconstruction with special tumour endoprostheses. Orthopade. 2020; 49(2): 142-8. doi:10.1007/ s00132-020-03872-1.

14. Allison D, Huang E, Ahlmann E, Carney S, Wang PA-C L, Menendez L. Peri-prosthetic infection in the orthopedic tumor patient. Reconstr Rev. 2014; 4(3): 13-7. doi: 10.15438/rr.v4i3.74.

15. Parvizi J, Tan TL, Goswami K, Higuera C, Della Valle C, Chen AF, Shohat N. The 2018 definition of periprosthetic hip and knee infection: an evidence-based and validated criteria. J Arthroplasty. 2018; 33(5): 1309-14.e2. doi: 10.1016/j.arth.2018.02.078.

Conflictos de intereses: Los autores declaran que no tienen conflictos de intereses al realizar esta publicación. 